\title{
Protein $S$ activity in women with unexplained infertility
}

\author{
Original Mohammed S. El-Sokkary, Bassem A. Islam, Esraa G. Alshawadfy \\ Article \\ Department of Obstetrics and Gynecology, Faculty of Medicine, Ain-Shams University, Cairo, \\ Egypt
}

\begin{abstract}
Aim: To the best of our knowledge, no previous studies have addressed the association of unexplained infertility with protein $\mathrm{S}$ activity. This case-control study was performed to evaluate the prevalence of protein S activity in women with unexplained infertility and to compare its prevalence in normal fertile women.

Materials and Methods: This is a case-control study conducted to evaluate the prevalence of protein S activity in women with unexplained infertility conducted at Ain-Shams University Maternity Hospital. A total of 30 women with unexplained primary infertility and another 30 fertile women of matched age group as their control were recruited from September 2018 to March 2019. Using STA Compact Max ${ }^{\circledR}$ Coagulation System protein S was measured. STA-staclot kit supplied by Stago, France is a clotting assay for measuring protein S activity in human citrated plasma. A venous blood sample $(3 \mathrm{ml})$ was collected from every participant at any day of the menstrual cycle then the samples were collected in $(3.2 \%)$ sodium citrate tubes (venous blood must be mixed with the sodium citrate immediately after collection by turning upside down gently the tube 3 or 4 times), then centrifugation performed as fast as possible less than an hour to obtain platelet-poor plasma and centrifuged at $2500 \mathrm{~g}$ for $15 \mathrm{~min}$ (platelet poor plasma). Samples and test reagents are loaded into the instrument where sample handling, reagent delivery, analysis, and reporting of results are performed automatically.

Results: This study failed to find a relationship between protein S activity and unexplained infertility compared to the normal fertile population. Despite finding none in the unexplained infertility sample population with protein S deficiency and one in the control group, this difference failed to reach significance.

Conclusion: In conclusion, this study failed to find any association between protein S activity and unexplained infertility but this study showed that the mean of protein S percentage in group 1 (cases) is lower than the mean in group 2 (controls).
\end{abstract}

Key Words: Protein S, thrombophilia and infertility, unexplained infertility

Received: 29 November 2019, Accepted: 14 January 2020

Corresponding Author: Esraa G. Alshawadfy, Department of Obstetrics and Gynecology, Faculty of Medicine, Ain-Shams University, Egypt, Tel.: 01007955707, E-mail: esraaalshawadfy@gmail.com

ISSN: 2090-7265, November 2020, Vol. 10, No. 4

\section{INTRODUCTION}

Infertility is a condition in which successful pregnancy would not occur, despite normal intercourse over 12 months. Approximately 9 to $18 \%$ of normal couples are infertile ${ }^{[1]}$. Up to $30 \%$ of couples with infertility have unexplained infertility, meaning no cause for infertility was discovered after evaluation of ovulation, sperm parameters, fallopian tube patency, and uterine anatomy ${ }^{[2]}$. Unexplained infertility refers to the absence of a definable cause for a couple's failure to achieve pregnancy ${ }^{[3]}$. Previous studies showed that the presence of any of the following inherited thrombophilias: protein S deficiency, protein C deficiency, prothrombin G20210A, factor V Leiden, methylenetetrahydrofolate reductase (MTHFR) or antithrombin III deficiency was more common in recurrent implantation failure patients, especially in unexplained infertility (UI), when compared with fertile control group ${ }^{[4]}$. The presence of a genetic defect in one of the major contributing components (protein $\mathrm{C}$, protein $\mathrm{S}$, and antithrombin) to thrombophilia can be determined by clinical laboratory assays ${ }^{[5]}$.

Failed implantation accounts for the largest group of failed in-vitro fertilization (IVF) cycles ${ }^{[7]}$. It is biologically plausible that inherited and acquired thrombophilias negatively affect embryonic vascularization and implantation ${ }^{[6,7]}$. Soligo and colleagues' study is limited by lack of intent-to-treat analysis. As the literature focuses on a wide array of thrombophilia contributors, finding directly comparable studies can be difficult ${ }^{[8,9]}$. Nonetheless, the literature supported the presence of a single inherited thrombophilia as a promoter for recurrent IVF failure ( 2 to 6 failed cycles) $\mathrm{OR}=3.15, p=0.00,95 \%$ confidence Interval $[\mathrm{CI}]$ : $1.74-5.70^{[7]}$. The literature also supported an association between a single inherited 
or acquired thrombophilic factor and unexplained infertility $p<0.01$ and greater association with at least two thrombophilic factors $p<0.0001^{[10]}$. In contrast with the convenience sample of IVF patients analyzed by Soligo and colleagues, a prospective study of 96 infertile Iranian women associates Factor $\mathrm{V}$ Leiden with recurrent failed IVF, OR $=3.06$, $p=0.01,95 \%$ CI: $1.26-10.27^{[7]}$. Similarly, a prospective case-control study of 140 Egyptian women found an association between Factor V Leiden and unexplained infertility $p=0.04^{[10]}$.

Due to the poor information available concerning the relationship between inherited thrombophilia and infertility, a case-control study was performed to evaluate the prevalence of protein S activity in women with unexplained infertility.

\section{PATIENTS AND METHODS}

Study design: This case-control study was conducted at Ain-Shams University Maternity Hospital from September 2018 March 2019.

Thirty women in total with unexplained primary infertility were recruited from the infertility outpatient clinic. Another 30 fertile women who got pregnant at least once in the previous year were recruited from outpatient gynecology clinic as control.

Approval: The study was approved by the ethical committee of the Department of Obstetrics and Gynecology, Ain-Shams University and informed written consents were obtained from all participants before the commencement of the study.

Diagnosis: Women with unexplained infertility were diagnosed when absence of male factor; normal semen analysis $>20$ million sperm per $\mathrm{mL}$ with more than $50 \%$ of the sperms showing forward motility and more than $30 \%$ normal morphology. Adequate ovulation based either on a mid-luteal serum progesterone level greater than 10ng/ $\mathrm{mL}$, or serial transvaginal ultrasounds to monitor the development and rupture of a dominant ovarian follicle. Normal FSH, LH, TSH, prolactin. Normal uterine cavity and patent tubes as proved by hysterosalpingography or laparoscopic findings.

Procedure: STA-staclot kit supplied by Stago, France. is a clotting assay for measuring Protein $\mathrm{S}$ activity in human citrated plasma.

Sample Collection: A venous blood sample $(3 \mathrm{ml})$ was collected from every participant at any day of the menstrual cycle.
The samples were collected in $(3.2 \%)$ sodium citrate tubes, (venous blood must be mixed with the sodium citrate immediately after collection by turning upside down gently the tube 3 or 4 times).

Centrifugation: Performed as fast as possible less than an hour to obtain platelet-poor plasma and centrifuged at $2500 \mathrm{~g}$ for $15 \mathrm{~min}$ (platelet poor plasma).

Assay type: Assays for functional protein S are indirect and are based on prolongation of blood clotting by the generation of activated protein $\mathrm{C}$ and its function in the assay ${ }^{[11]}$.

\section{Sample size justification and statistical analysis:}

The sample size was calculated using Epi Info ${ }^{\circledR}$ version 6.0, setting the power $(\beta)$ at $80 \%$ and the significance level $(\alpha)$ at 0.05 . The data from a previous study Bellver et al. (2008) was designed to explore the implication of thrombophilia and thyroid autoimmunity in three common and contentious problems encountered in reproductive medicine; namely, unexplained infertility, implantation failure and recurrent spontaneous abortion) (unexplained infertility $n=31$ ) $(\text { control group } n=32)^{[13]}$.

Calculations according to this value produce a minimal sample size of 30 women in each group. Statistical analysis was done using Stata $($ version 11 (StataCorp LP, College Statation, TX, USA) and MedCalc $\mathbb{C}$ version 12.2.1.0 (MedCalc Software, Mariakerke, Belgium). The D'Agostino Pearson test was performed to test the normality of numerical data distribution. The D'Agostino Pearson test was performed to test the normality of numerical data distribution. Normally distributed numerical data are presented as mean and SD. Qualitative data are presented as number and percentage. For normally distributed numerical data, the independentsamples (unpaired) Student t-test was used to compare the difference in the means between the two study groups. The Pearson chi-square test was used for comparison of the two groups as regards differences in categorical data. Fisher's exact test was used in place of the chi-square test if $>20 \%$ of the cells in any contingency table had an expected count of $<5 . P<0.05$ was considered statistically significant.

\section{RESULTS}

A total of 30 women with unexplained infertility was included as group I. The second set of 30 fertile control women was included as group II. This study failed to find any association between protein $\mathrm{S}$ activity and unexplained infertility. Comparison of protein $\mathrm{S}$ activity and incidence of protein $\mathrm{S}$ deficiency among the two groups; group I $n=30$ and group II $n=30$. 
The difference between the mean of protein $\mathrm{S}$ percentage in cases and controls. This study showed that the mean of protein S percentage in group I (cases) is lower than the mean in group II (controls).

Data are presented as number (\%). There was no statistically significant difference between women in both groups regarding age and body mass index.

There was also no significant difference between the two groups regarding protein $\mathrm{S}$ activity or incidence of protein $\mathrm{S}$ deficiency (Tables 1, 2 and 3).

Table 1: Comparison of protein $\mathrm{S}$ deficiency as regard number and percentage in cases and controls

\begin{tabular}{|c|c|c|c|c|c|}
\hline Group & \multicolumn{2}{|c|}{ Cases $(n=30)$} & \multicolumn{3}{|c|}{ Controls $(\mathrm{n}=30)$} \\
\hline Variable & Number & Percentage & Number & Percentage & $P$ value \\
\hline Protein S deficiency & zero & $0 \%$ & 1 & $3.33 \%$ & 0.157 \\
\hline
\end{tabular}

Table 2: Comparison of Protein S activity $\%$ mean in cases and controls

\begin{tabular}{lccccc}
\hline Group & \multicolumn{2}{c}{ Cases (n=30) } & \multicolumn{3}{c}{ Controls $(\mathrm{n}=30)$} \\
\hline Variable & Mean & SD & Mean & SD & Pvalue \\
Protein S activity\% & 98.11 & 11.93 & 104.22 & 10.48 & .039 \\
\hline
\end{tabular}

Table 3: Demographic data: Comparison between cases and controls as regard age and BMI

\begin{tabular}{lccccc}
\hline Group & \multicolumn{2}{c}{ Cases $(\mathrm{n}=30)$} & & Controls $(\mathrm{n}=30)$ \\
\hline Variable & Mean & SD & Mean & SD & P value \\
Age (yr.) & 27.47 & 4.62 & 27.03 & 4.45 & 0.713 \\
BMI $\left(\mathrm{kg} / \mathrm{m}^{2}\right)$ & 27.33 & 4.79 & 27.43 & 4.86 & 0.936 \\
\hline
\end{tabular}




\section{DISCUSSION}

Infertility is a condition in which a successful pregnancy has not occurred, despite normal intercourse over 12 months. Approximately 9 to $18 \%$ of normal couples are infertile ${ }^{[1]}$. Up to $30 \%$ of couples with infertility have unexplained infertility, meaning no cause for infertility was discovered after evaluation of ovulation, sperm parameters, fallopian tube patency, and uterine anatomy ${ }^{[2]}$. Unexplained infertility refers to the absence of a definable cause for a couple's failure to achieve pregnancy ${ }^{[3]}$. Attention is being paid to the association between inherited thrombophilia and infertility, and few studies, performed on small series of subjects, investigating the relationship between thrombophilia and unexplained infertility, are available $)^{[14]}$. Protein $\mathrm{S}$ is a vitamin $\mathrm{K}$-dependent protein, unlike the other vitamin $\mathrm{K}$-dependent plasma proteins, Protein $\mathrm{S}$ is not a serine protease. Protein $\mathrm{S}$ inhibits coagulation by acting as a cofactor for both tissue factor pathway inhibitor and activated protein C. Therefore, it is not surprising that a deficiency of protein $\mathrm{S}$ predisposes to venous thrombosis ${ }^{[12]}$.

Many studies suggested that thrombophilia was higher in women with unexplained infertility than in controls.

One study concluded that no statistically significant differences between patients with unexplained infertility and fertile women.

However, in the current study, the quantitative protein $\mathrm{S}$ activity percentage was statistically significant in patients of group II (control) when compared to patients of group I (cases) where the mean of protein $\mathrm{S}$ activity percentage $(\%)$ in cases is lower than in controls, with $P$ value 0.039.

While, the qualitative protein $\mathrm{S}$ activity showed no statistically significant difference between the two groups regarding protein $\mathrm{S}$ activity or incidence of protein S deficiency, with $P$ value 0.157 .

Due to the poor information available concerning the relationship between inherited thrombophilia and infertility, a case-control study was performed to evaluate the prevalence of protein $\mathrm{S}$ activity in women with unexplained infertility.

Thirty women as study group (group I) with unexplained primary infertility defined as an inability to conceive despite regular marital life for at least 12 months were recruited from infertile women attending outpatient infertility clinic.
Thirty fertile (group II) control women recruited from outpatient gynaecology clinic who got pregnant at least in the last year.

In the present study, the mean age of included cases was $27.47 \pm 4.62$ years and the mean age of included women of group II (controls) was $29.03 \pm 8.9$ years. The minimum was 20 years and the maximum was 35 years. This result is consistent with Bellver and his colleagues (2008) in which the control group included 32 women of 18-35 years of age and unexplained infertility group less than 38 years of age.

On the other hand, Fatini and his colleagues (2012) found that the median age was 35 years ranging from 18 to 46 years of age. This may be attributed to the late age of marriage in the Italian population.

In the present study, the mean BMI was $27.33 \pm 6.78 \mathrm{Kg} / \mathrm{m}^{2}$, the minimum being 21 and the maximum was 35 . This result is consistent with Sweed and his colleagues (2017) in which the mean BMI was $26.01 \pm 3.35 \mathrm{Kg} / \mathrm{m}^{2}$, the minimum being 19.6 and the maximum was 32.41 .

There was no statistically significant difference between women of both groups regarding age and BMI denoting that both groups are matched regarding the demographic data.

The mean of the duration of infertility in the present study in women with unexplained infertility was $3.9 \pm 2.1$ years. This agrees with Fatini and his colleagues (2012) who found that the median of infertility years was 4 years and Bellver and his colleagues (2008) found the mean to be $3.4 \pm 2.3$ years.

In this study, Gravidity in control group $(n=30)$ was as the following; participants who got pregnant once were $8(26.6 \%)$, twice were $7(23.33 \%), 3$ times (G3) were $9(30 \%),(\mathrm{G} 4, \mathrm{G} 5)$ were $2(6.67 \%)$ and $(\mathrm{G} 6, \mathrm{G} 7)$ were $1(3.33 \%)$.

While, parity in the control group $(n=30)$ was as the following; controls who delivered once (P1) were 8 (26.6\%), who delivered twice (P2) were 9 (30\%), who delivered for 3 times (P3) were $7(23.33 \%), 4$ times (P4) were $3(10 \%)$ and (P5, P6, P7) was 1 participant only $(3.33 \%)$.

Three participants only from the control group $(n=30)$ had previous one abortion $(10 \%)$, the rest of the controls had no previous abortions. 
Number of women having alive children in the control group $(n=30)$ is as the following; controls with 1 child are $8(26.6 \%)$, with 2 children is $9(30 \%)$, with 3 children is $7(23.33 \%)$, with 4 children is $4(13.33 \%)$, with 6 children is $1(3.33 \%)$ and with 7 children is $1(3.33 \%)$.

As regards previous IVF in cases, only one participant $(3.33 \%)$ from the cases group $(n=30)$ had one unsuccessful previous IVF.

As regard cutoff value, the best cutoff value in this study is 100, which indicated the following; participants with protein $\mathrm{S}$ activity level below the cutoff value are less fertile while participants with protein $\mathrm{S}$ activity level above the cutoff value are more fertile.

Cases $(n=30)$ number and percentage below cutoff value are $17(56.67 \%)$, cases number and percentage above cutoff value are $13(43.33 \%)$, controls number and percentage below cutoff value are $9(30 \%)$ and controls number and percentage above cutoff value are $21(70 \%)$.

Total participants in this study $(n=60)$ number and percentage below cutoff value are $26(43.33 \%)$ while the total number and percentage above cutoff value are $34(56.67 \%)$.

As regard protein $\mathrm{S}$ titer, normal protein $\mathrm{S}$ activity range from 65 to $135 \%$. Patients with low normal protein $\mathrm{S}$ activity titer in cases $(\mathrm{n}=30)$ were $4(13.33 \%)$ while in controls $(n=30)$ were zero $(0 \%)$.

Patients with moderate normal protein $\mathrm{S}$ activity titer in cases $(n=30)$ are $22(73.33 \%)$ which is as same as in controls $(\mathrm{n}=30) 22(73.33 \%)$.

Finally, patients with high normal protein S activity titer in cases are $4(13.33 \%)$ while in controls $(n=30)$ are $7(23.33 \%)$. Protein S deficiency in cases was zero $(0 \%)$ while in controls was $1(3.33 \%)$.

It was important to study the hormonal profile of both groups with special emphasis on FSH, LH, progesterone, TSH and prolactin.

The mean FSH among cases of unexplained infertility was $6.55 \pm 1.97$, while in control group was $6.19 \pm 2.1$. This result is consistent with Sweed and his colleagues (2017) in which the mean FSH among cases of unexplained infertility was $7.27 \pm 2.2$, while in control group was $7.19 \pm 2.4$.
The results were within normal ranges and the difference was not significant statistically between cases and controls regarding FSH level.

Mean LH among cases was $6.8 \pm 3.38$, while in controls was $6.6 \pm 3.25$. This result is consistent with Sweed and his colleagues (2017) in which the mean LH among cases was $6.8 \pm 2.17$, while in controls was $7.18 \pm 2.25$.

The results were within normal ranges and the difference was not significant statistically between cases and controls regarding $\mathrm{LH}$ level.

Mean progesterone among cases was $18.32 \pm 2.35$, while in the control group it was $17.88 \pm 2.48$. This result is consistent with Sweed and his colleagues (2017) in which the mean progesterone among cases was $18.22 \pm 2.3$, while in the control group it was $17.88 \pm 2.48$.

The results were within normal ranges and the difference was not significant statistically between cases and controls regarding progesterone level.

Mean TSH among cases was $2.62 \pm 2.2$, while in controls was $2.54 \pm 2.24$. This result is consistent with Sweed and his colleagues (2017) in which the mean TSH among cases was $1.77 \pm 0.76$, while in controls was $1.53 \pm 0.52$.

The results were within normal ranges and the difference was not significant statistically between cases and controls regarding TSH level.

Mean prolactin among cases of unexplained infertility was $16.89 \pm 5.16$, while in control group was $16.58 \pm 3.5$. This result is consistent with Sweed and his colleagues (2017) in which the mean prolactin among cases of unexplained infertility was $15.52 \pm 4.81$, while in control group it was $16.55 \pm 3.5$.

The results were within normal ranges and the difference was not significant statistically between cases and controls regarding prolactin level.

All results were within normal ranges and the difference was not significant statistically between cases and controls regarding the above-mentioned hormones. That may exclude any factor affecting fertility other than protein S deficiency.

In this study, studied the protein S activity in both groups using clotting assay, the assay with a normal 
range from 65 to $135 \%$, this method is the same method as Bellver and his colleagues (2008) where functional protein $\mathrm{S}$ levels were measured using clotting assay (normal range from 50 to $120 \%$ ).

The current study showed that there was a statistically significant difference between the two groups regarding protein $\mathrm{S}$ levels in both groups, in group I (cases), mean protein $\mathrm{S}$ level was $98.11 \pm 23.86$, and in group II was $104.22 \pm 20.96$, $P$-value was 0.039 which was statistically significant.

Azim and his colleagues (2004) study showed that the presence of any of the following inherited thrombophilias: protein $\mathrm{S}$ deficiency, protein $\mathrm{C}$ deficiency, prothrombin G20210A, factor V Leiden, methylenetetrahydrofolate reductase (MTHFR), or antithrombin III deficiency, was more common in recurrent implantation failure patients, especially in unexplained infertility (UI), when compared with fertile control group.

Also, this study determined the prevalence of protein $\mathrm{S}$ deficiency in cases and controls which was (zero) patients $(0 \%)$ in group I and one woman with protein S deficiency $(3.33 \%)$ in group II, with $P$ value 0.157 which was statistically not significant. These results were similar with Bellver and his colleagues (2008), who discovered only one patient with protein $\mathrm{S}$ deficiency in cases $(3.2 \%)$ and three women in controls with protein $\mathrm{S}$ deficiency $(9.4 \%)$, which was statistically not significant.

However, Azim and his colleagues (2004) studied a group of 45 women with a history of more than or 4 failed IVF cycles, in whom at least 3 good quality embryos were transferred, and found an incidence of inherited thrombophilia of $44.4 \%$ in comparison to that of $18.2 \%$ among fertile controls. A subgroup of 21 cases in the implantation failure group with unexplained infertility presented an even higher incidence of thrombophilia both with $(61.9 \%)$ and without $(42.8 \%)$ the inclusion of the most prevalent condition (homozygous MTHFR mutation).

In Spain, Bellver and his colleagues (2008) study was designed to explore the implication of thrombophilia and thyroid autoimmunity in three common and contentious problems encountered in reproductive medicine, namely unexplained infertility, implantation failure and recurrent spontaneous abortion.

From March 2004 to January 2007, 119 women were prospectively included; 32 as control group and 31 patients with unexplained infertility, 26 with implantation failure and 30 with recurrent spontaneous abortion.
The implantation failure and recurrent spontaneous abortion groups presented normal preimplantation genetic screening. Protein $\mathrm{C}$, protein $\mathrm{S}$, antithrombin III, lupus anticoagulant, activated protein $\mathrm{C}$ resistance (APCR),immunoglobulin $\mathrm{M}$ and $\mathrm{G}$ anticardiolipin antibodies, homocysteine, Factor V Leiden, prothrombin G20210A mutation, methylenetetrahydrofolate reductase C677T mutation, thyroid-stimulating hormone (TSH), free thyroxine, anti-thyroid peroxidase (TPO) and anti-thyroglobulin (TG) antibodies were assessed.

Bellver and his colleagues (2008) found that women with unexplained infertility did not show a higher incidence of thrombophilia than the other groups, the lack of significant differences between unexplained infertility and implantation failure groups and the control group could be related to the sample size of the study.

The current study showed statistically no significant correlation between protein $\mathrm{S}$ activity and age, body mass index, FSH level, LH level, TSH level, progesterone level, prolactin level and AMH among the studied cases.

Based on this current debate about the usefulness of routine investigation of inherited thrombophilia in infertile women, further studies performed in larger samples of infertile women, are needed to elucidate and validate this issue and if confirmed to propose interventional clinical trials.

\section{CONCLUSION}

In conclusion, this study failed to find any association between protein $\mathrm{S}$ activity and unexplained infertility.

However, this study showed that the mean of protein $\mathrm{S}$ percentage in group 1 (cases) is lower than the mean in group 2 (controls). Still, this pilot study included a limited number of participants and didn't investigate other thrombophilia markers to assess their relationship with unexplained infertility, especially that others have demonstrated the relationship between other inherited thrombophilia markers and unexplained infertility.

\section{CONFLICT OF INTEREST}

There are no conflicts of interests.

\section{REFERENCES}

1. Aghajanova L, Hoffman J, Mok Lin E and Herndon CN. Obstetrics and gynecology residency and fertility needs. Reprod Sci.2017; 24:428-34. 
2. Cookingham LM, Van Voorhis BJ and Ascoli M. Do alterations in follicular fluid proteases contribute to human infertility? J Assist Reprod Genet.2015; 32(5):737-45. doi: 10.1007/s10815015-0447-9. Epub 2015 Feb 15.

3. Yücel B, Kelekci S and Demirel E. Decline in ovarian reserve may be an undiagnosed reason for unexplainedinfertility: a cohort study. Arch Med Sci. 2018 Apr;14(3):527-531.

4. Patounakis G, Bergh E, Forman EJ, Tao X, Lonczak A, Franasiak JM, Treff N and Scott RT Jr. Multiple thrombophilic single nucleotide polymorphisms lack a significant effect on outcomes in fresh IVF cycles: an analysis of 1717 patients. J Assist Reprod Genet. 2016 Jan;33(1):67-73.

5. Marlar RA and Gausman JN. Laboratory testing issues for protein $\mathrm{C}$, protein $\mathrm{S}$, and antithrombin. Int J Lab Hematol.2014 Jun;36(3):289-95.

6. Soligo AG, Barini R and Bizzacchi JA. Inherited and Acquired Thrombophilia and Infertility in a Population of Brazilian Women. Int $\mathrm{J}$ Reprod Fertil Sex Health. 2016 Oct 31;3(5):86-90.

7. Safdarian L, Najmi Z, Aleyasin A, Aghahosseini M, Rashidi $\mathrm{M}$ and Asadollah S. Recurrent IVF failure and hereditary thrombophilia. Iran $\mathbf{J}$ Reprod Med. 2014 Jul;12(7):467-70.

8. Djurovic J, Stojkovic O, Todorovic J, Brajic A, Stankovic S and Obradovic S. Genetics of suspected thrombophilia in Serbian females with infertility, including three cases, homozygous for FII 20210A or FV 1691A mutations. Hum Fertil (Camb). 2017 Jun;20(2):132-139. doi: 10.1080/14647273.2016.1255785. Epub 2016 Nov 18

9. Goldstajn MS and Kovacević D. The effect of trombophilia on pregnancy outcome and IVF success. Coll Antropol. 2014 Dec;38(4):1153-61.
10. Soliman AT and Nayel EM. Evaluation of the potential role of inherited and acquired thrombophilia in unexplained infertility. Journal of Evidence-Based Women's Health Journal Society. 2014 Aug 1;4(3):149-54.

11. Alshaikh NA, Rosing J, Thomassen MCLGD, Castoldi E, Simioni P and Hackeng TM. New functional assays to selectively quantify the activated protein $\mathrm{C}$ - and tissue factor pathway inhibitor-cofactor activities of protein $\mathrm{S}$ in plasma.J Thromb Haemost. 2017 May; 15(5): 950-960. doi: 10.1111/jth.13657. Epub 2017 Mar 20.

12. Mulder R, de Vries JK, Müskens RPHM, Mulder $\mathrm{AB}$ and Lukens MV. High protein S activity due to C4b-binding protein deficiency in a 34-yearold Surinamese female with ischemic retinopathy. Clin Case Rep: 2018 May; 6(5): 935-938.

13. Bellver J, Soares SR, Alvarez C, Muñoz E, Ramírez A, Rubio C, Serra V, Remohí J and Pellicer A. The role of thrombophilia and thyroid autoimmunity in unexplained infertility, implantation failure and recurrent spontaneous abortion. Hum Reprod. 2008; 23(11):2614.

14. Sweed MS, Serag-Eldin IF and Tharwat Wafa I. Protein C Activity in Women with Unexplained Infertility. Journal of Advanced Medical Sciences and Applied Technologies.2017; 3(2):121-124.

15. Fatini C, Conti L, Turillazzi V, Sticchi E, Romagnuolo I, Milanini MN, Cozzi C, Abbate R and Noci I. Unexplained infertility: association with inherited thrombophilia. Thromb Res. 2012; 129(5): e185-8.

16. Azem F, Many A, Ben Ami I, Yovel I, Amit A, Lessing JB and Kupferminc MJ. Increased rates of thrombophilia in women with repeated IVF failures. Hum Reprod. 2004 Feb;19(2):368-70. 